\title{
Effort to Improve Science Learning Outcomes with Scientific Approach in SDN 3 Randurejo
}

\author{
Sunarti \\ SDN 3 Randurejo \\ sunar87ti@gmail.com
}

\section{Article History}

accepted $14 / 11 / 2020$

approved $21 / 11 / 2020$

published 26/11

\begin{abstract}
This Classroom Action Research aims to improve the learning outcomes of Class $V$ students in learning Healthy Food through the application of a scientific approach to Class V Students of SD Negeri 3 Randurejo, Pulokulon District, Grobogan Regency Academic Year 2020/2021. To achieve this goal, a study was conducted. The research in question is a type of classroom action research (PTK) with the dependent variable, namely, increasing the learning outcomes of grade $V$ students in learning the Healthy Food Theme at SD Negeri 3 Randurejo for the academic year 2020/2021, while the independent variable is the use of PPT media through a scientific approach. The data collection techniques used were interviews, observation and learning outcomes tests. After the data collected will be analyzed using comparative descriptive, while for qualitative data analyzed using qualitative descriptive analysis based on the results of observation and reflection. In this classroom action research (CAR), each cycle consists of planning, implementing, observing and reflecting. With the research subjects totaling 11 students, in cycle I there were 6 students (54.54\%) who completed learning, in Cycle II student learning completeness increased to students (72.72\%), in cycle III student learning completeness increased to 10 students (90.90\%). By looking at the learning outcomes, the application of science can improve student learning outcomes
\end{abstract}

Keywords: Scientific approach, learning outcomes

\begin{abstract}
Abstrak
Penelitian Tindakan Kelas ini bermaksud untuk meningkatkan hasil belajar siswa Kelas $V$ dalam pembelajaran Makanan Sehat melalui penerapan pendekatan saintifik pada Siswa Kelas V SD Negeri 3 Randurejo Kecamatan Pulokulon Kabupaten Grobogan Tahun Pelajaran 2020/2021.Untuk mencapai tujuan tersebut, dilakukan suatu penelitian. Penelitian yang dimaksud adalah jenis penelitian tindakan kelas (PTK) dengan variabel terikat yaitu, meningkatkan hasil belajar siswa kelas $\mathrm{V}$ dalam pembelajaran Tema Makanan Sehat di SD Negeri 3 Randurejo Tahun Pelajaran 2020/2021, sedangkan untuk variabel bebasnya adalah penggunaan Media PPT melalui pendekatan saintifik. Teknik pengumpulan data yang digunakan adalah wawancara, observasi dan tes hasil belajar. Setelah data terkumpul akan dianalisis dengan menggunakan deskriptif komparatif, sedangkan untuk data kualitatif dianalisis menggunakan analisis deskriptif kualitatif berdasarkan hasil observasi dan refleksi.Dalam penelitian tindakan kelas (PTK) ini, setiap siklusnya terdiri dari perencanaan, pelaksanaan, observasi dan refleksi. Dengan subjek penelitian yang berjumlah 11 siswa, pada siklus I terdapat 6 siswa $(54,54 \%)$ yang tuntas belajar, pada Siklus II ketuntasan belajar siswa meningkat menjadi siswa $(72,72 \%)$, pada siklus III ketuntasan belajar siswa meningkat menjadi 10 siswa $(90,90 \%)$. Dengan melihat hasil belajar tersebut, maka penerapan saintifik dapat meningkatkan hasil belajar siswa.
\end{abstract}

Kata kunci: Pendekatan saintifik, Hasil Belajar

Social, Humanities, and Education Studies (SHEs): Conference Series https://jurnal.uns.ac.id/shes

p-ISSN 2620-9284

e-ISSN 2620-9292

This work is licensed under a Creative Commons Attribution-ShareAlike 4.0 International License. 


\section{PENDAHULUAN}

Sesuai dengan Undang-Undang Sisdiknas No. 20 Tahun 2003 pasal 1 disebutkan bahwa pendididkan adalah usaha sadar dan terencana untuk mewujudkan suasana belajar dan proses pembelajaran agar peserta didik secara aktif mengembangkan potensi dirinya untuk memiliki kekuatan spiritual keagamaan, pengendalian diri, kepribadian, kecerdasan, aklak mulia, serta ketrampilan yang diperlukan dirinya, masyrakat, bangsa dan negara. Secara umum sekolah dasar diselenggarakan dengan tujuan untuk mengembangkan sikap dan kemampuan serta memberikan pengetahuan dan ketrampilan dasar yang diperlukan untuk hidup dalam masyarakat serta mempersiapkan peserta didik mengikuti pendidikan menengah.

Menurut Trianto, Hakikat IPA dibangun atas dasar produk ilmiah, proses ilmiah, dan sikap ilmiah. Trowbidge dan Bybee dalam Ika Kartika, IPA sebagai tubuh pengetahuan Berdasarkan diagram tersebut, Trowbidge dan Byebee dalam Ika Kartika mendefinisikan IPA sebagai berikut: Science is body of knowledge formed by of continous inquiry, and compassing the people who are engaged in the scientific enterprise. Hakikat belajar IImu Pengetahuan Alam (IPA) adalah melatih peserta didik menjadi saintis untuk melakukan penemuan baru terhadap fenomena alam sehingga menemukan produk ilmiah yang baru melalui proses ilmiah dan berlandaskan sikap ilmiah. Produk ilmiah baru yang dimaksud berupa fakta, konsep, generalisasi, prinsip, teori dan hukum (Arikunto, 2013:365). Sains menurut Acesta (2014:39) merupakan pengetahuan hasil kegiatan manusia yang bersifat aktif dan dinamis tiada hentihentinya serta diperoleh melalui metode tertentu yaitu teratur, sistematis, berobjek ,bermetode, dan berlaku secara universal. Pendekatan saintifik (scientific approach) adalah model pembelajaran yang menggunakan kaidah-kaidah keilmuan yang memuat serangkaian aktivitas pengumpulan data melalui observasi, menanya, eksperimen, mengolah informasi atau data, kemudian mengkomunikasikan (Kemendikbud, 2014).

Berdasarkan latar belakang yang telah dikemukakan, maka perumusan masalah dalam penelitian ini adalah bagaimana meningkatkan hasil belajar IPA materi makanan sehat dengan pendekatan saintifik pada siswa kelas V di SD Negeri 3 Randurejo Tahun Pelajaran 2020/2021?" dan Apakah pendekatan saintifik dapat meningkatkan hasil belajar IPA materi makanan sehat pada siswa kelas V di SDN 3 Randurejo Tahun Pelajaran 2020/2021?"

Tujuan dari penelitian ini adalah Mendeskripsikan langkah pendekatan saintifik dalam meningkatkan hasil belajar IPA materi Makanan Sehat pada siswa kelas V SD Negeri 3 Randurejo Tahun Pelajaran 2020/2021 dan Meningkatkan hasil belajar IPA materi Makanan Sehat melalui pendekatan saintifik pada siswa kelas $\mathrm{V}$ SDN 3 Randurejo Tahun Pelajaran 2020/2021.

\section{METODE}

Jenis penelitian ini adalah Penelitian Tindakan Kelas (PTK). Menurut Wardhani, IGAK (2007: 4) PTK adalah bentuk penelitian yang dilakukan oleh guru di dalam kelasnya sendiri melalui refleksi diri, dengan tujuan untuk memperbaiki kinerjanya sebagai guru, sehingga hasil belajar siswa menjadi meningkat.

Penelitian ini dilaksanakan selama 3 bulan yaitu bulan Oktober, Nopember dan Desember 2020. Bulan Oktober peneliti mulai mengadakan persiapan, yaitu menyusun prosposal penelitian dan instrumennya. Bulan Nopember peneliti sudah mulai melaksanakan penelitian tindakan kelas siklus I dan siklus II. Bulan Desember peneliti melakukan tindakan kelas siklus IIldan mulai membuat laporan hasil penelitian.

Menurut Arikunto (2013: 161) data adalah segala fakta dan angka yang dapat dijadikan bahan untuk menyusun suatu informasi. Jenis data yang terdapat pada penelitian tindakan kelas ini berupa nilai hasil belajar siswa sebagai data kuantitatif dan informasi tentang proses pembelajaran IPA dengan menerapkan pendekatan saintifik 
tentang makanan sehat sebagai data kualitatif dan Menurut Arikunto (2013: 172), "Sumber data adalah subjek dari mana data dapat diperoleh". Data yang digunakan peneliti dalam penelitian tindakan kelas ini adalah data yang tepat dan relevan yaitu terdiri dari siswa, guru dan dokumen.

Teknik pengumpulan data dapat dilakukan dalam berbagai setting, berbagai sumber, dan berbagai cara. Apabila dilihat dari segi cara atau teknik pengumpulan data, maka teknik pengumpulan data dapat dilakukan dengan teknik tes dan nontes (Sugiyono, 2015: 193). Teknik analisis data terdiri dari analisis data kualitatif dan analisis data kuantitatif.

\section{HASIL DAN PEMBAHASAN}

Bagian ini sebanyak 800-1000 kata. Pada bagian pembahasan, diuraikan hasil kajian/penelitian dan hubungannya dengan kerangka teori atau kajian empirik terdahulu. Pada bagian ini dapat mnyertakan tabel dan gambar secara ringkas. Contoh penyajian tabel dan gambar sebagai berikutBerdasarkan hasil tes formatif pembelajaran Tema Makanan Sehat Mata pelajaran IPA siklus I pada hari Senin, tanggal 16 November 2020. Dengan tindakan siklus I diperoleh peningkatan hasil belajar siswa. Untuk memperjelas dapat dilihat pada tabel berikut ini.

Tabel 1. Nilai Siklus I

\begin{tabular}{cccc}
\hline No & Nilai & Frekuensi & Persentase \\
\hline 1 & $\geq 70$ & 6 & $54,54 \%$ \\
2 & $60-69$ & 3 & $27,27 \%$ \\
3 & $50-59$ & 2 & $18,18 \%$ \\
4 & $40-49$ & 0 & $0,00 \%$ \\
& Jumlah & 11 & $100 \%$ \\
\hline
\end{tabular}

Dari analisa nilai hasil tes pada tabel 3 dapat dibuat diagram batang seperti pada gambar berikut.

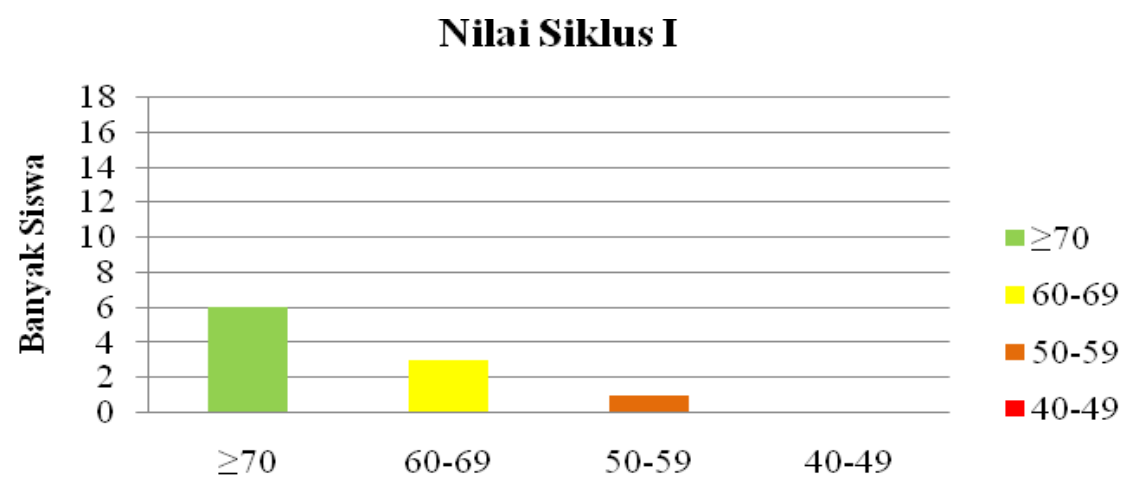

Rentang Nilai

Gambar 1. Grafik Hasil Tes Formatif Siklus 1

Dari hasil yang diperoleh pada siklus I ini kurang baik, dengan nilai rata-rata 65 nilai tertinggi 70 nilai terendah 50. Siswa yang mendapat nilai di atas 70 adalah 6 siswa dari 11 siswa, ketuntasan $54,54 \%$ belum tuntas $45,45 \%$, perlu peningkatan. Hal ini disebabkan karena siswa baru mengetahui pembelajaran daring melalui zoom. Pada siklus I peneliti menekankan pada penggunaan media powerpoint melaluipendekatan saintifik. Peneliti akan mengkondisikan kelas sebaik mungkin dan melibatkan siswa. 
Berdasarkan hasil tes formatif siklus I, selanjutnya dilakukan tindakan pembelajaran Tema Makanan Sehat Mata pelajaran IPA siklus II pada hari Senin, tanggal 23 Nopember 2020. Penelitian pada siklus II ini peneliti memperoleh data peningkatan hasil belajar siswa. Nilai rata-rata yang diperoleh adalah 70 . Dari nilai rata-rata itu, masih ada beberapa siswa yang belum mencapai KKM yang telah ditetapkan yaitu $\geq 70$. Dari hasil ini perlu peningkatan.

Agar lebih jelas perhatikanlah peningkatan hasil belajar siswa pada siklus II berikut ini.

Tabel 2. Nilai Siklus II

\begin{tabular}{cccc}
\hline No & Nilai & Frekuensi & Persentase \\
\hline 1 & $\geq 70$ & 8 & $72,72 \%$ \\
2 & $60-69$ & 3 & $27,27 \%$ \\
3 & $50-59$ & 0 & $0,00 \%$ \\
4 & $40-49$ & 0 & $0,00 \%$ \\
& Jumlah & 11 & $100 \%$ \\
\hline
\end{tabular}

Dari analisa nilai hasil tes pada tabel 4 dapat dibuat diagram batang seperti pada gambar berikut.

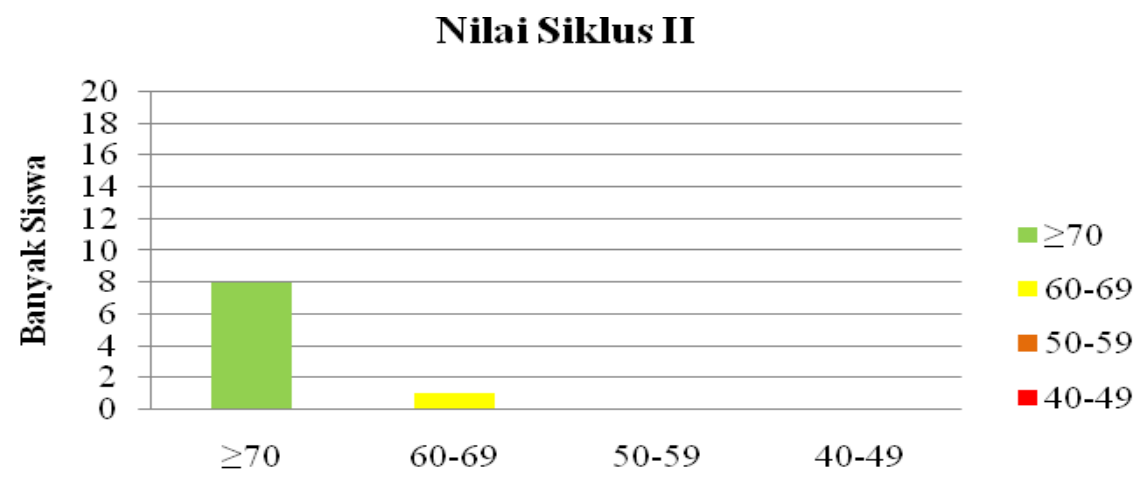

Rentang Nilai

Gambar 2. Grafik Hasil Tes Formatif Siklus II

Dari hasil yang diperoleh pada siklus II ada peningkatan hasil. Nilai rata-rata 75 , nilai tertinggi 80 , nilai terendah 60 . Siswa yang mendapat nilai $\geq 70$ adalah 8 siswa dari 11 siswa. Ketuntasan yang dicapai $72.72 \%$ yang belum tuntas $27.27 \%$. Hal ini disebabkan karena jaringan anak kurang mendukung, hal ini menyebabkan anak kebingungan pada saat mengerjan tugas.

Karena belum mencapai kriteria keberhasilan yaitu ketuntasan klasikal belum mencapai $\geq 80 \%$ maka tindakan akan dilanjutkan pada siklus III. Peneliti akan mengkodisikan kelas sebaik mungkin, menekankan pada media powerpoint dan mengoptimalkanpendekatan saintifik dengan melibatkan siswa serta memperhatikan pada siswa yang masih bermasalah dengan jaringan akan saya kondisikan ditempat yang benar-benar sinyalnya bagus.

Tabel 3. Nilai Siklus III

\begin{tabular}{cccc}
\hline No & Nilai & Frekuensi & Persentase \\
\hline 1 & $\geq 70$ & 10 & $90,90 \%$ \\
2 & $60-69$ & 1 & $9,09 \%$ \\
3 & $50-59$ & 0 & $0,00 \%$ \\
4 & $40-49$ & 0 & $0,00 \%$ \\
\hline
\end{tabular}




\begin{tabular}{lll}
\hline Jumlah & 11 & $100 \%$ \\
\hline
\end{tabular}

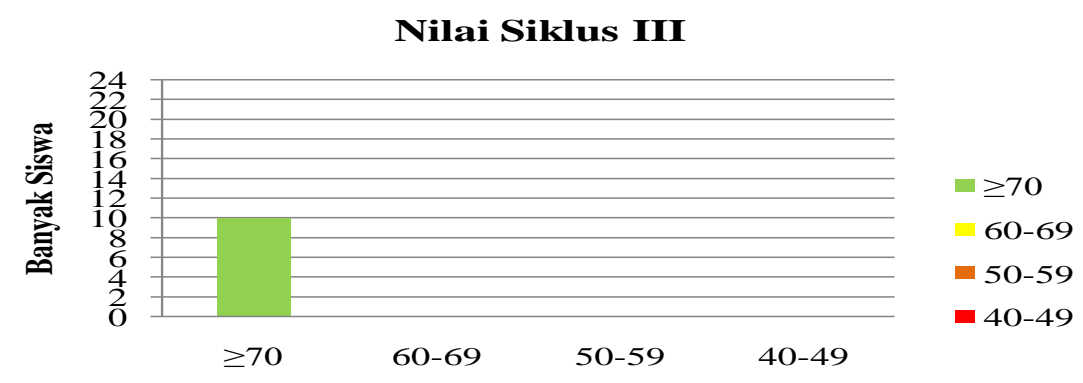

Rentang Nilai

Gambar 5. Grafik Hasil Tes Formatif Siklus III

Dari hasil yang diperoleh pada siklus III ada peningkatan hasil. Nilai rata-rata 85 , nilai tertinggi 100 , nilai terendah 70 . Siswa yang mendapat nilai $\geq 70$ adalah 10 siswa dari 1 siswa. Ketuntasan yang dicapai 90,90\% yang belum tuntas 9,09\%. Ketuntasan klasikal ada peningkatan yang sangat signifikan. Karena sudah mencapai kriteria keberhasilan yaitu ketuntasan klasikal yaitu $\geq 80 \%$ maka tindakan pembelajran selesai pada siklus III.

\section{SIMPULAN}

Berdasarkan rumusan masalah, hasil penelitian, dan pembahasan penerapan pendekatan saintifik pada siswa kelas V SD Negeri 3 Randurejo tahun ajaran 2020/2021 diperoleh simpulan sebagai berikut: Mendeskripsikan langkah pendekatan saintifik dalam meningkatkan hasil belajar IPA materi Makanan Sehat pada siswa kelas V SD Negeri 3 Randurejo Tahun Pelajaran 2020/2021 dan Meningkatkan hasil belajar IPA materi Makanan Sehat melalui pendekatan saintifik pada siswa kelas $V$ SDN 3 Randurejo Tahun Pelajaran 2020/2021

Pada awal pembelajaran menggunakan media powerpoint melalui zoom dengan pendekatan saintifik pada siklus I ketuntasan 54,54\% (6 siswa ) dari 11 siswa, siklus II ada kenaikan ketuntasan menjadi $72,72 \%$ (8 siswa) dari 11 siswa dan siklus III ada kenaikan ketuntasan menjadi 90,90\% (10 siswa) dari 11 siswa.

Peningkatan ini menunjukkan bahwa hipotesis tindakan yang menyatakan bahwa: "Dengan Penggunaan Media powerpoint melalui zoom dengan pendekatan saintifik dapat MeningkatkanHasil Belajar Siswapada Pembelajaran IPA materi pembelajaran Makanan Sehat pada Siswa Kelas V SD Negeri 3 Randurejo Tahun Pelajaran 2020/2021" ternyata terbukti kebenarannya.

\section{DAFTAR PUSTAKA}

Acesta, A. (2014). Penerapan Pendekatan Keterampilan Proses Sains Untuk Meningkatkan Hasil Belajar Siswa Dalam Pembelajaran IPA. Jurnal IImiah Pendidikan Dasar. Diakses pada 05 April 2018, dari http://jurnal.unissula.ac.id/index.php/pendas/article/view/743

Altabany, Trianto, (2015). Mendesain Model Pembelajaran Inovatif, Progeresif dan Kontekstual. Surabaya: Prenadamedia Group. Asmani, J.M. (2016). TipeEfektif Cooperative Learning.

Arikunto,Suharsimi.2010. Prosedur Penelitian Suatu Pendekatan Praktik.Jakarta : Rineka Cipta 


\section{SHEs: Conference Series 3 (3) (2020) $1358-1363$}

Kartika, Ika, (2018).Pengembangan Lembar Kerja Peserta Didik (LKPD) ipa Terpadu Berbasis Model Iqra' Dan Mitigasi Bencana Erupsi Merapi. Study Program of Islamic Elementary Education, sunan kalijaga State Islamic University, (2018)

Kemendikbud. 2014. Konsep dan Implementasi Kurikulum 2013. Jakarta: Kementrian Pendidikan dan Kebudayaan.

Sugiyono (2015). Metode Penelitian Kombinasi (Mix Methods). Bandung: Alfabeta.

Undang-undang Republik Indonesia (2003). Undang - undang RI Nomor 20 Tahun 2003, tentang Sistem Pendidikan Nasional.

Wardani,Igak. (2007). Penelitian Tindakan Kelas. Jakarta: Universitas Terbuka KTSP SD/MI 2011 